Die alkalische Diacetylreaktion ist eine allgemeine Reaktion für Guanidine, bei denen mindestens eine freie Aminogruppe vorhanden sein muß (6). Der Einfluß von Arginin, Methylguanidin und Glycocyamin auf die Spezifität der Reaktion in bezug auf Kreatin wurde deshalb geprüft. Diese Substanzen sollen bei Raumtemperatur etwa $10 \%$ ihrer Konzentration an Kreatin vortäuschen (1). Durch Senkung der Reaktionstemperatur konnte die Spezifität der alkalischen Diacetylreaktion verbessert werden. Glycocyamin und Arginin täuschen weniger als 3,5\% der Farbausbeute gleicher Mengen an Kreatin vor. Durch den Einfluß dieser Substanzen werden also unter unseren Bedingungen und bei normaler Ausscheidung durch die Niere $(10,11)$ etwa nur $4 \mathrm{mg} / \mathrm{Tag}$ Kreatin zuviel gemessen (Tab. 3). Auf nicht mehr als $10 \mathrm{mg}$ steigt dieses "scheinbare Kreatin“ bei erhöhter Exkretion Guanidogruppen enthaltender Verbindungen z. B. bei der progressiven Muskeldystrophie an $(12,13)$. Bei der gleichzeitig stark vermehrten Kreatinausscheidung spielt diese Menge eine geringe Rolle. Selbst bei der enzymatischen Methode mit Kreatinphosphokinase wird Glycocyamin zu 2,5\% miterfaßt (1). Diese Methode benötigt außerdem viel Ausgangsmaterial und die Wiederfindungsquote liegt zwischen $86 \%$ und $110 \%$ (1). Einen Einfluß anderer potentieller Stör-
Tab. 3

Einfluß von Störsubstanzen auf die Kreatinbestimmung bei $7,5^{\circ}$

\begin{tabular}{|c|c|c|c|}
\hline Substanz & $\begin{array}{c}\text { Konzentration } \\
{[\mathrm{ppm}]}\end{array}$ & $\begin{array}{c}\text { scheinbare } \\
\text { Kreatin- } \\
\text { konzentration } \\
\text { [ppm] }\end{array}$ & $\begin{array}{c}\text { Farbintensität } \\
\text { in \% der } \\
\text { Kreatin- } \\
\text { reaktion }\end{array}$ \\
\hline $\begin{array}{l}\text { Glycocyamin } \\
\text { Arginin } \\
\text { Methylguanidin } \\
\text { Harnstoff } \\
\text { Harnsäure* } \\
\text { Cystin } \\
\text { Andere Aminosäuren }\end{array}$ & $\begin{array}{r}200 \\
100 \\
1000 \\
20000 \\
500 \\
100 \\
100\end{array}$ & $\begin{array}{r}7 \\
3 \\
25 \\
0 \\
0 \\
0 \\
0\end{array}$ & $\begin{array}{l}3,5 \\
3 \\
2,5 \\
0 \\
0 \\
0 \\
0\end{array}$ \\
\hline
\end{tabular}

* Harnsäure allein senkt die Grundlinie. In Gegenwart von Kreatin $(20 \mathrm{ppm})$ ergibt sich keine meßbare Verminderung der Farbintensität.

substanzen wie Harnsäure, Harnstoff und verschiedener Aminosäuren (7) ließ sich in unserem Verfahren nicht nachweisen und der Harn mußte nicht - zur Ausschaltung von Störsubstanzen $(6,9)-$ verdünnt werden.

$\mathrm{Da}$ die Umwandlung des Kreatinins in den harnableitenden Wegen in der gleichen Größenordnung wie der durch Störsubstanzen bedingte Fehler liegt, scheint uns eine chromatographische $(14,15)$ oder elektrophoretische (16) Abtrennung des Kreatins, um die Genauigkeit zu erhöhen, nicht sinnvoll. Bei der Untersuchung von Serum treten die Störfaktoren und der Fehler, der durch das Kreatinin bedingt ist, nicht mehr hervor.

\title{
Literatur
}

1. Lauber, K., diese Z.. 3, 119 (1966). - 2. Dunicz, B. L., Clin. chim. Acta Amsterdam 9, 203 (1964). - 3. BENEDICT, S. R., J. biol. Chemistry 18, 191 (1914). - 4. Barritt, M. M., J. Pathol. Bacteriol. 42, 441 (1936). - 5. Eggleton, P.,'S. R. ElsDEN und N. Gough, Biochem. J. 37, 526 (1943). - 6. RAafLAuB, J. und I. Abelin, Biochem. Z. 321, 158 (1950). - 7. Kanig, K., HoppeSeyler's Z. physiol Chem. 306, 247 (1957). - 8. Berndt, E., H. U. Bergmeyer und H. MöLlering in H. U. Bergmeyer: Methoden der enzymatischen Analyse, S. 407, Verlag Chemie, Weinheim (1962). - 9. Griffith, W. J., Clin. chim. Acta (Amsterdam)
9, 213 (1964). - 10. Wissenschaftliche Tabellen Geigy 1960, 6. Auflage. - 11. ANDEs, J. E. und V. C. MYrers, J. Laborat. Clin. Med. S. Louis 22, 1447 (1937). - 12. Sullivan, M. X., W. C. Hess und F. Irreverre, J. biol. Chemistry 114, 633 (1936). 13. HobermanN, H. D., E. A. H. Sims und W. W. Engstrom, J. biol. Chemistry 173, III (1948). - 14. Paumgartner G., O. Kraupp und F. X. Fischer, Clin. chim. Acta (Amsterdam) 8, 960 (1963). - 15. RiNk, M. und D. KRebBer, J. Chromatogr. 21, 143 (1966). - 16. Fischl, J., S. Segal und Y. Yulzari, Clin. chim. Acta (Amsterdam) 10, 73 (1964).

Priv.-Doz. Dr. G. Gundlach 665 Homburg (Saar) Universitätskliniken

\section{Zur Eliminierung von Trübungsfehlern bei der Eiweißbestimmung mit der Biuretmethode}

\author{
Von Ch. Bode, H. Goebell und E. StähLER \\ Aus der Mediqinischen Universitätsklinik Marburg/Labn (Direktor: Prof. Dr. G. A. Martini)
}

(Eingegangen am 5. April 1968)

\begin{abstract}
1. Der blaue Biuretkomplex wird durch KCN-Zusatz komplett entfärbt. Diese Reaktion wird dazu benutzt, Lipidtrübungen in Eiweißlösungen zu erfassen und Fehler zu eliminieren. Die Methode ist einfach, wenig zeitaufwendig und liefert gut reproduzierbare Ergebnisse. 2. Störende Farbstoffbeimengungen (Hämoglobin) können mit der Methode ebenfalls ausgeschaltet werden.

3. Die Höhe der trübungsbedingten Fehler wird für Mitochondrien verschiedener Organe und menschliches Serum mit unterschiedlichem Lipidgehalt bestimmt.
\end{abstract}




\section{The elimination of errors caused by turbidity in the determination of protein by the biuret method}

1. The blue Biuret-complex is completely decolourized by the addition of $\mathrm{KCN}$. This chemical reaction has been exploited to eliminate faults in biuret-protein determination caused by lipid-turbidity in protein-solutions. The method is simple, it takes little time, and the results show good reproducibility.

2. The effect of interfering pigments (haemoglobin) in protein solutions can be eliminated by the same method.

3. The errors produced by turbidity in protein-containing samples were determined for mitochondria of different organs and for human serum containing different amounts of lipids.

Zur Bestimmung der Eiweißkonzentration im Serum, in anderen biologischen Flüssigkeiten und Gewebshomogenaten wird heute die Biuretmethode allgemein benutzt $(1,2,3,4)$. Sie ist, seit Weichselbaum (3a) den Kupfer-Tartratkomplex als Reagenz angegeben hat, in der Durchführung einfach und liefert gut reproduzierbare Ergebnisse. Mögliche Fehlerquellen durch unterschiedlich zusammengesetzte Eiweißkörper $(1,5)$ oder höhere Ammoniumsulfatkonzentrationen in der $\mathrm{zu}$ untersuchenden Lösung (6) wurden beschrieben und können berücksichtigt werden.

Ein Problem blieb bisher jedoch die Eliminierung von Fehlern, die durch Trübung (vorwiegend durch Lipidbeimengungen) oder durch die Gegenwart von Farbstoffen in der zu testenden Probe entstehen. Zur Entfernung von störenden Lipidtrübungen wurden verschiedene Verfahren vorgeschlagen, wie Ausschütteln mit Äther $(3,7,8)$, Waschen des Eiweißniederschlages mit einem Petroläther-Äthanolgemisch oder Zusatz von Desoxycholat zu dem Biuretansatz $(9,10)$. Die genannten Verfahren sind umständlich, zeitaufwendig und liefern zum Teil auch schlecht reproduzierbare Ergebnisse.

Zur Erfassung von Trübungsfehlern wurde von Szarkowskea und KLINGENBERG das Entfärben des Biuretansatzes durch KCN-Zugabe vorgeschlagen (11). In der vorliegenden Untersuchung prüften wir die Brauchbarkeit dieser Methode.

\section{Material und Methoden}

Albumin reinst bezogen wir von den Behringwerken Marburg/L.; Aldolase von Biochemica Boehringer, Tutzing; Haemoglobin reinst von Serva, Heidelberg. Alle weiteren Chemikalien stammten von dẹ Fa. Metck, Darmstadt (p. a. oder reinst). Zur Herstellung der Fettemulsion wurde Butterfett verwendet.

$\beta$-Hydroxy-Buttersäure-Dehydrogenase (EC 1.1.1.30) war ein angereichertes Enzym aus Pseudomonas sphaeroides (12).

1. Die Biuretbestimmung erfolgte nach der von BEIsENHERz und Mitarbeitern (5) angegebenen Methode mit der Abänderung, daß wir zu der zu untersuchenden Probe $2,5 \mathrm{ml}$ Biuretreagenz zusetzten und nach Beendigung der Reaktion nach 30 Min. zum Endvolumen von $5 \mathrm{~m} l$ auffüllten. Die Mitochondriensuspensionen: (entsprechend $0,5-5 \mathrm{mg}$ Protein) wurden mit bidest. Wasser auf etwa $1 \mathrm{ml}$ aufgefüllt und das Eiweiß mit $0,2 \mathrm{ml} 50$ proz. (w/v) Trichloressigsäure gefällt. Durchh Zentrifugation (10 Min., $20000 \mathrm{~g}$ ) und Dekantieren des Überstandes wurde der Niederschlag gewonnen. Er wurde unter ständigem Rühren bei Raumtemperatur in der angegebenen Menge Biuretreagenz gelöst. Bei Serumeiweißbestimmungen wurden entweder $0,1 \mathrm{~m} /$ unbehandeltes Serum eingesetzt, oder wie bei den Mitochondriensuspensionen, das Eiweiß ausgefällt. Die Extinktion wurde bei $546 \mathrm{~nm}, d=$ $2 \mathrm{~cm}$, im Photometer Eppendorf abgelesen. Leerwerte wurden bei jedem Testansatz mitbestimmt. Hier wurde statt der Eiweißlösung die gleiche Menge bidest. Wasser eingesetzt. Der Protein- gehalt berechnet sich dann: $\mathrm{f} \cdot(\Delta \mathrm{E} \mathrm{Meßwert}-\Delta \mathrm{E}$ Leerwert $)=$ mg Protein/Testansatz (nach BeIsenherz und Mitarbeiter ist $\mathrm{f}=8,75$ ).

2. $K C N$-Zugabe: Zunächst wurde wie unter 1. verfahren. Nach Ablesen der Extinktion ( $\triangle \mathrm{E}_{1}$ ) wurden etwa $30 \mathrm{mg} \mathrm{KCN}$ in Substanz eingerührt. Vollständige Entfärbung des Biuretkomplexes wurde spätestens nach $5 \mathrm{Min}$. erreicht, und die Extinktion des farblosen Testansatzes wurde erneut gemessen $\left(\Delta \mathrm{E}_{2}\right)$. Zusatz von weiteren $20 \mathrm{mg} \mathrm{KCN}$ änderte die Extinktion nicht weiter. Entsprechend wurde bei den Leerwerten verfahren. Die Berechnung der Proteinkonzentration geschah nach folgender Gleichung:

$\mathrm{f} \cdot\left(\Delta \mathrm{E}_{1} \mathrm{M}-\Delta \mathrm{E}_{2} \mathrm{M}\right)-\left(\Delta \mathrm{E}_{1} \mathrm{~L}-\Delta \mathrm{E}_{2} \mathrm{~L}\right)=\mathrm{mg}$ Protein/Testansatz $\mathrm{M}=$ Meßwert; $\mathrm{L}=$ Leerwert.

3. Ausscbuitteln mit Ätber: $\mathrm{Zu}$ dem nach 1. fertig gelösten Biuretansatz wurden in einem Zentrifugenglas $2 \mathrm{ml}$ A thyläther gegeben, mit der Hand kräftig geschüttelt und anschließend $3 \mathrm{Min}$. in der Christ-Tischzentrifuge bei 3000 U./Min. zentrifugiert. Die Biuretlösung wurde zur Messung der Extinktion durch einen vorsichtig durch die verbliebene Ätherschicht geführten dünnen Polyäthylenschlauch abgesaugt, der Blindwert wurde entsprechend behandelt.

4. Waschen mit Petrolätber-Athanolgemisch: Das durch Trichloressigsäure-Fällung und Zentrifugation gewonnene Eiweiß-Pellet wurde in $4 \mathrm{ml}$ Petroläther-Äthanolgemisch (1:1) suspendiert und $30 \mathrm{Min}$. lang kräftig gerührt (Magnetrührer). Nach Rezentrifugation und Dekantieren des Petroläther-Alkohol-Uberstandes wurde das gewaschene Eiweißpellet wie bei 1. weiter verarbeitet.

5. Die Isolierung der Mitochondrien erfolgte nach früher beschriebenen Verfabren (12).

6. Die $N$-Bestimmung nach KJELDAHL erfolgte nach RAPpAporT und Mitarbeiter (13). Zur Umrechnung von Stickstoff auf Protein wurde der Faktor 6,25 benutzt (4).

\section{Ergebnisse}

1. Ausschluß von Lipidtrübungen durch $\mathrm{KCN}$-Zusatz Mit steigendem Lipidgehalt einer Eiweißlösung nimmt der Trübungsgrad und damit der Fehler für die mit der Biuretmethode ermittelte Eiweißkonzentration zu. Dies zeigt der in Abbildung 1 wiedergegebene Versuch. Biuretansätzen der gleichen Albuminlösung werden steigende Mengen einer Neutralfettemulsion zugesetzt. Der Fehler durch die Lipidtrübung nimmt bis zu einem Neutralfettgehalt von $10 \mathrm{mg} /$ Ansatz proportional zur Fettmenge und bei noch höheren Lipidkonzentrationen etwas langsamer zu. Durch KCN-Zusatz kann die Lipidtrübung ermittelt und selbst bei hohen Lipidkonzentrationen fast vollständig eliminiert werden. Die Differenz zwischen den Werten mit und ohne $\mathrm{KCN}-$ Zugabe bei reinem Albumin beträgt in diesem Fall 5\%. Bei verschiedenen Albuminchargen lag die Höhe des trübungsbedingten Fehlers zwischen 3 und $9 \%$ (Tab. 1).

\section{Vergleich mit anderen Methoden}

Wie Abbildung $2 \mathrm{zu}$ entnehmen ist, läßt sich die Trübung durch Neutralfettzusatz zu einer Albuminlösung 
auch durch Waschen des Eiweißniederschlages, den man nach der Trichloressigsäurefällung und Zentrifugation erhält, mit einem Petroläther-Äthanolgemisch relativ gut erfassen.

Ausschütteln des Biuretansatzes mit Äther ergibt etwa gleiche Ergebnisse wie die Petroläther-Äthanolbehandlung (Abb. 2). Für höhere Lipidkonzentrationen ist die letztgenannte Methode besser geeignet.

Durch Zusatz von 10proz. (w/v) Taurocholat in einer Menge bis $0,2 \mathrm{~m} l$ pro Ansatz wurde nur eine unzureichende Reduktion der Lipidtrübung beobachtet.

\section{Erfassen von Fehlern durch Farbstoffverunreinigung}

Fehler in der Eiweißbestimmung mit der Biuretmethode werden nicht nur durch Trübung der zu untersuchenden Lösung hervorgerufen, sondern auch durch Farbstoffe, die im gleichen Spektralbereich Licht absorbieren wie der Biuretkomplex (z. B. Hämoglobin und Cytochrome). Wie Abbildung $2 \mathrm{zu}$ entnehmen ist, steigt der Fehler bei der Eiweißbestimmung nach der Biuretmethode

Tab. 1

Suspensionen verschiedener Mitochondrien und Proteinlösungen mit und ohne Eliminieren des Trübungsfehlers durch KCN-Zugabe. Werte mit $\mathrm{KCN}=100 \%$. $\mathrm{n}=$ Anzahl der untersuchten Proben. In Klammern Min.-Max. Werte des prozentualen Fehlers. Einzelheiten siehe Text

\begin{tabular}{lcccc}
\hline \multicolumn{1}{c}{$\begin{array}{c}\text { Protein bestimmt } \\
\text { in }\end{array}$} & $\mathrm{n}$ & $\begin{array}{c}\text { Biuret-Protein } \\
\text { Mittelwerte (g/l) } \\
\text { mit KCN } \\
\text { ohne KCN }\end{array}$ & $\begin{array}{c}\% \text { Fehler } \\
\text { ohne KCN }\end{array}$ \\
\hline $\begin{array}{l}\text { Rattenleber-Mito- } \\
\text { chondrien }\end{array}$ & 21 & 44,7 & 67,1 & $50(28-86)$ \\
$\begin{array}{l}\text { Rattenherz-Mito- } \\
\text { chondrien }\end{array}$ & 13 & 16,5 & 25,1 & $52(41-66)$ \\
$\begin{array}{l}\text { Rattenskelettmuskel- } \\
\text { Mitochondrien }\end{array}$ & 7 & 14,9 & 21,3 & $43(20-65)$ \\
$\begin{array}{l}\text { Locustenflugmuskel- } \\
\text { Mitochondrien }\end{array}$ & 7 & 14,3 & 23,1 & $62(43-82)$ \\
$\begin{array}{l}\text { Albuminlösung } \\
\begin{array}{l}\text { Aldolase-Suspension } \\
\text { B-Hydroxybutyrat- }\end{array}\end{array}$ & 4 & 49,5 & 47,2 & $4,8(2,9-9,2)$ \\
$\begin{array}{l}\text { Dehydrogenase- } \\
\text { Präparation }\end{array}$ & 1 & 9,4 & 9,3 & 1,1 \\
\hline
\end{tabular}

proportional mit zunehmendem Hämoglobingehalt an. Bei niedrigen Hämoglobinkonzentrationen läßt sich dieser Fehler durch KCN-Zusatz fast vollständig, bei höheren Hämoglobinkonzentrationen bis auf $3 \%$ beheben. Ähnliche Ergebnisse erhielten wir bei Cytochrom-c-Zusatz zu Eiweißlösungen.

Wie bei der geringen Lichtabsorption durch Bilirubin bei $546 \mathrm{~nm} \mathrm{zu}$ erwarten ist, stört diese Substanz die Biuretbestimmung bis zu einer relativ hohen Konzentration $(20 \mathrm{mg} / 100 \mathrm{ml}$ im Serum). nicht. KCN-Zusatz ändert die durch Bilirubin hervorgerufene Lichtabsorption bei dieser Wellenlänge nicht.

\section{Proteinwerte verschiedener Mitochondriensuspen-} sionen und Seren

In Tabelle 1 sind Mittelwerte der mit der Biuretmethode gewonnenen Proteinkonzentrationen mit und ohne $\mathrm{KCN}=$ Zusatz für Mitochondriensuspensionen verschiedener Organe zusammengestellt. In der rechten Spalte sind die Fehler in \% eingetragen, die ohne Berücksichtigung des Trübungs- bzw. Farbstoffanteils an der gemessenen Extinktion entstehen $(100 \%=$ Proteinkonzentration mit der KCN-Methode). Für Mitochondrien aus Rattenleber und Rattenherz liegt der Fehler im Durchschnitt bei $50 \%$, etwas geringer ist er für Mitochondrien aus Rattenskelettmuskel (43\%) und im Durchschnitt etwas höher für Mitochondrien aus Locusten-Flugmuskel (62\%). Bei Mitochondrien aus Kalbszwerchfell liegt er in der gleichen Größenordnung wie für Locusten-Flugmuskel. Bei Lösungen von reinem Albumin liegt der Fehler bei $5 \% . \mathrm{Da}$ der durch die Biuretreaktion ermittelte wahre Proteingehalt durch $\mathrm{KCN}-Z u s a t z$ nicht geändert wird, zeigen schließlich die Werte, die mit einem kristallisierten (Aldolase EC 4.1.2.7), oder hochgereinigten Enzym ( $\beta$-Hydroxybutyrat-Dehydrogenase) erhalten wurden (Tab. 1).

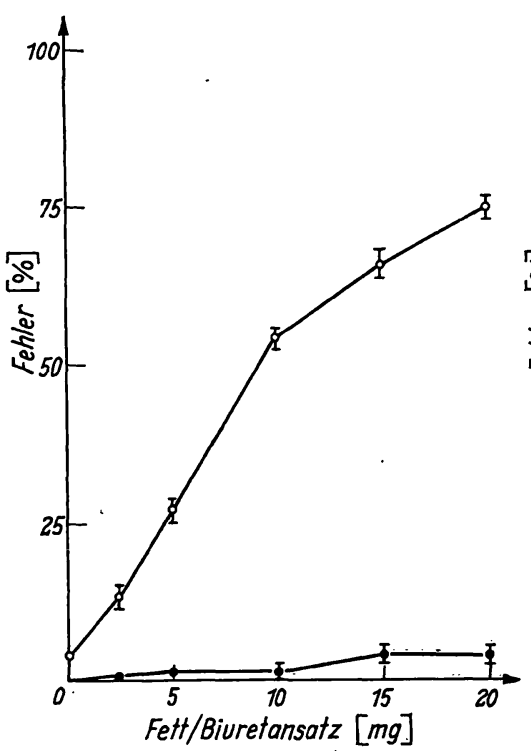

Abb. 1

Fehler der Biuretbestimmung durch Lipidtrübung; Abhängigkeit von der Lipidkonzentrubung; Abhangigkeit von der LipidkonzenKCN-Zusatz (•) Einzelheiten s. Text

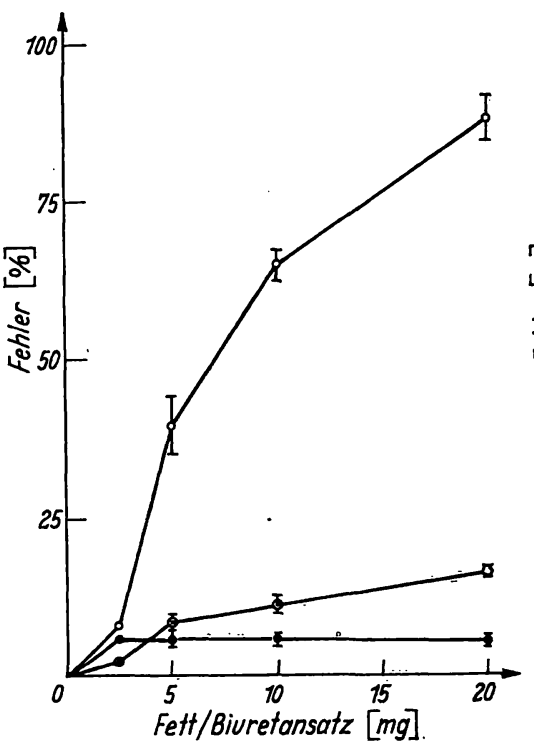

Abb. 2 Ausschütteln mit Ather $\odot$ bzw. Petroläther
Áthanolwäsche (๑) zur Eliminierung von FehAthanolwäsche (o) zur Eliminierung von Fehlern durch Lipidtrubungen bei der Eiweißbestimmung mit der Biuretmethode. $0-0=$ un
behandelter Ansatz. Einzelheiten s. Text

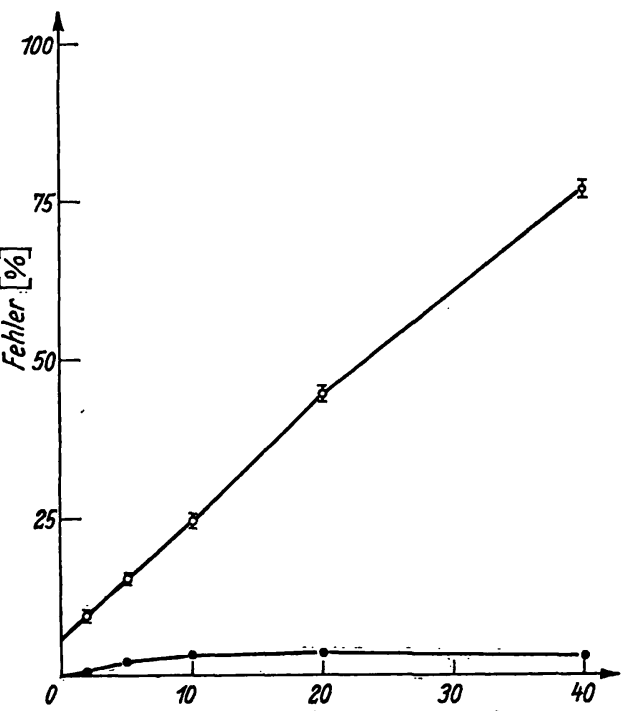

Hb-gehalt . (mg/ml EiweiBlösung)

Abb. 3

Fehler der Biuretbestimmung durch Farbstoffbeimengung (Hb); Abhängigkeit von der Haemoglobinkonzentration (o) und Eliminieren des Fehlers durch KCN-Zusatz (०). 
Tab. 2

Vergleich der mit und ohne KCN-Zusatz gewonnenen Proteinkonzentrationen bei hyperlipämischen Seren. Biuretbestimmung, Einzelheiten siehe experimenteller Teil

\begin{tabular}{ccccc}
\hline $\begin{array}{c}\text { Patient } \\
\text { Nr. }\end{array}$ & $\begin{array}{c}\text { Neutralfett } \\
(\mathrm{mg} / 100 \mathrm{ml})\end{array}$ & $\begin{array}{c}\text { Serum-Proteinkonzen- } \\
\text { tration }(\mathrm{g} / 100 \mathrm{ml}) \\
\text { mit KCN } \\
\text { ohne KCN }\end{array}$ & $\begin{array}{c}\text { \% Fehler* } \\
\text { ohne KCN }\end{array}$ \\
\hline 1 & 1428 & 7,88 & 11,2 & 42 \\
2 & 916 & 6,64 & 9,61 & 45 \\
3 & 828 & 8,16 & 11,6 & 42 \\
4 & 684 & 9,81 & 13,1 & 33 \\
5 & 676 & 6,94 & 9,35 & 35 \\
6 & 735 & 6,91 & 8,55 & 24 \\
7 & 616 & 5,58 & 7,51 & 35 \\
8 & 612 & 6,23 & 7,96 & 28 \\
9 & 480 & 6,97 & 8,12 & 17 \\
10 & 324 & 7,09 & 8,32 & 18 \\
\hline Mittelwert & 730 & 7,20 & 9,53 & 32 \\
\hline
\end{tabular}

*Proteinkonzentration mit $\mathrm{KCN}=100 \%$

Auch bei der quantitativen Eiweißbestimmung im Serum können Lipidtrübungen und Farbstoffbeimengungen zu Fehlern führen. In Tabelle 2 sind die Gesamteiweißkonzentrationen im Serum von 10 Patienten mit Hyperlipämie mit und ohne KCN-Zusatz wiedergegeben. Mit Zunahme der Lipidkonzentration werden auch die Fehler größer. Im Mittel liegen die Werte ohne $\mathrm{KCN}$ bei einer ausgeprägteren Hyperlipämie deutlich zu hoch.

Weniger ausgeprägt sind mit durchschnittlich $12 \%$ die Abweichungen bei der Bestimmung des Serumgesamteiweißes durch Trübung usw. bei 93 unausgesuchten Seren eines Routinelabors (Tab. 3). Werden die in

Tab. 3

Differenzen der Gesamteiweißkonzentration im Serum mit und ohne KCN-Zusatz. Untersucht wurden 93 unausgewählte Seren eines Routine-Labors.

A Mittelwert sämtlicher Seren

B Mittelwert von Seren, die leichte Hämolyse zeigten C Mittelwert von ikterischen Seren

\begin{tabular}{|c|c|c|c|c|}
\hline Seren & $\mathrm{n}$ & $\begin{array}{l}\text { Eiwei } \\
\text { mit } \mathrm{KCN} /\end{array}$ & $\begin{array}{l}\text { m Serum } \\
\text { ml) } \\
\text { ohne KCN }\end{array}$ & $\%$ Fehler* \\
\hline $\begin{array}{l}\mathrm{A} \\
\mathrm{B} \\
\mathrm{C}\end{array}$ & $\begin{array}{r}93 \\
7 \\
10\end{array}$ & $\begin{array}{l}6,57 \\
6,66 \\
6,61\end{array}$ & $\begin{array}{l}7,34 \\
7,71 \\
7,64\end{array}$ & $\begin{array}{l}11,8(6,9-32,6) \\
15,8(9-17) \\
15,6(7,0-23,7)\end{array}$ \\
\hline
\end{tabular}

* Wert mit $\mathrm{KCN}=100 \%$. In Klammern Min.-Max. des prozentualen Fehlers

diesem Durchschnittskollektiv enthaltenen ikterisch verfärbten Seren und solche, die eine leichte Hämolyse aufweisen, gesondert betrachtet, liegt die Differenz $z$ wischen der Bestimmung mit KCN-Zusatz und der üblichen Methode mit 15\% nur wenig höher (Tab. 3, B, C). Die in den Tabellen 2 und 3 wiedergegebenen Werte wurden nach Säurefällung des Eiweißes erhalten. Wird unbehandeltes Serum unmittelbar zur Eiweißbestimmung benutzt, sind die Trübungsfehler im Durchschnitt etwas niedriger.

\section{Biuretfaktor}

Zur Berechnung des Biuretfaktors wird in Albuminlösungen und Mitochondrienșuspenșionen der Proteingehalt mit der Kjeldahl-Methode bestimmit. Durch Division der auf diese Weise gewonnenen Werte durch die in einem Biuret-Parallel-Ansatz gefundene Extinktion läßt sich der Biuretfaktor bestimmen. Für Rinderalbuminlösung liegt er bei der Bestimmung ohne KCN-Zusatz bei 8,77 und nach KCN-Zusatz um $8 \%$ höher (Tab. 4). In der gleichen Tabelle sind noch die Biuretfaktoren für Mitochondrien aus Rattenleber und Taubenbrustmuskel angegeben. Sie betragen bei Verwendung der KCN-Methode jeweils 10,4.

Tab. 4

Biuretfaktor für verschiedene Proteine bezogen auf den Proteinwert aus Kjeldahlstickstoff. A Biuretansatz unbehandelt, B nach Eliminieren des Trübungsanteils durch KCN n = Anzahl' der Bestimmungen. Einzelheiten siehe Text

\begin{tabular}{|c|c|c|c|}
\hline \multirow{2}{*}{$\begin{array}{l}\text { Proteinlösung } \\
\text { (Mitochon- } \\
\text { driensuspension) }\end{array}$} & \multirow[b]{2}{*}{$\mathbf{n}$} & \multicolumn{2}{|c|}{ Biuretfaktor } \\
\hline & & unbehandelt & nach $\stackrel{\mathrm{B}}{\mathrm{KCN}}$ \\
\hline $\begin{array}{l}\text { Rinderalbumin } \\
\text { Rattenleber } \\
\text { Taubenmuskel }\end{array}$ & $\begin{array}{l}7 \\
4 \\
3\end{array}$ & $\begin{array}{l}8,77(8,27-9,34) \\
5,95(5,9-6,0) \\
3,44\end{array}$ & $\begin{array}{l}9,42 \\
10,4 \\
10,4\end{array}(10,90-9,92-10,5)$ \\
\hline
\end{tabular}

\section{Diskussion}

Zur Eiweißbestimmung in biologischem Material hat sich die Biuretmethode als zuverlässig erwiesen. Schwierigkeiten machte bislang der Ausschluß von Fehlern durch Trübung und Farbstoffbeimengungen in der zu untersuchenden Probe. Durch Entfärbung des blauen Biuretkomplexes mit KCN können nach der beschriebenen Methode auch sehr ausgeprägte Lipidtrübungen erfaßt und die sonst entstehenden Fehler korrigiert werden. Sie erfordert für Einzelmessungen einen Zeitaufwand von 3 bis 4 Min., bei einer größeren Anzahl von Bestimmungen ist er pro Einzelwert erheblich geringer. Damit eignet sich diese Methode auch für größere Laboratorien und Kliniken.

Bei einer Prüfung der von anderen Autoren angegebenen Methoden zur Eliminierung von Lipidtrübungen wie Ausschütteln des Ansatzes mit Äther $(3,7,8)$ oder Waschen des nach Denaturierung durch Zentrifugation gewonnenen Eiweißpellets mit einem Petroläther-Äthanolgemisch konnte bei sehr sorgfältigem Arbeiten ebenfalls der durch Lipidtrübung verursachte Fehler erfaßt werden. Bei niedrigeren Lipidkonzentrationen, in einem Bereich, wie sie etwa bei hyperlipämischen Seren zu finden sind, erwies sich die KCN-Methode jedoch als überlegen. Auch bei der Eiweißbestimmung in Mitochondriensuspensionen und Gewebshomogenaten ist die Petroläther-Äthanolwäsche zur Ausschaltung von Trübungsfehlern im Vergleich zur KCN-Methode weniger wirksam. Zudem erfordern diese Methoden einen erheblich größeren Zeitaufwand und die Ergebnisse sind schlechter reproduzierbar.

Von einigen Autoren wurden Gallensäuren als Detergens benutzt, um Lipidtrübungen auszuschalten $(9,10)$. Diese Methode erwies sich bei der jetzigen Prüfung als wenig erfolgreich.

Besonders wichtig ist die Ausschaltung von Trübungsfehlern bei Untersuchungsmaterial mit relativ hohem Lipidgehalt. Der trübungsbedingte Fehler liegt z. B. für Suspensionen von Mitochondrien aus verschiedenen Geweben zwischen 40 und $60 \%$ (Tab. 1). Da der Gesamteiweißgehalt neben dem Frischgewicht häufig als Bezugsgröße für den Gehalt weiterer Substanzen 
(z. B. Atmungskettenkomponenten, Adeninnucleotide usw.) benutzt wird $(8,11)$, ist eine Korrektur der bisher angegebenen Werte erforderlich, wenn der Trübungsanteil an der Extinktion bei der Eiweißbestimmung nicht berücksichtigt wurde. Aus den in Tabelle 1 angegebenen Werten kann für die Korrektur ein „KCN-Faktor" errechnet werden (für Rattenleber z. B. $f=1,5)$. Die starke Schwankung des Fehlers für Mitochondrien des gleichen Organs dürfte zum Teil auf den unterschiedlichen Lipidgehalt (Ernährungszustand, zeitlicher Abstand der letzten Mahlzeit vor dem Töten und Alter der Tiere) zum Teil auch auf unterschiedlich starke Beimengung anderer Zellorganellen („fluffylayer") zurückzuführen sein.

Auf kleinere Fehler der Gesamteiweißbestimmung im Serum nach der Biuretmethode wiesen FRANK und Mitarbeiter hin (1). Sie fanden relativ kleine Abweichungen durch pathologische Zusammensetzungen der Serumeiweißfraktionen und sehr hohe Bilirubinwerte. Auf die sehr viel größeren Änderungen bei Hyperlipämie gingen sie nicht ein. Bei einer mittelstarken Hyperlipämie liegt der trübungsbedingte Fehler um $30 \%$ (Tab. 2). Er ist etwas größer, wenn das Serumeiweiß, wie bei den in Tabelle 2 angegebenen Werten, vor der Zugabe von Biuretreagenz durch Trichloressigsäuere ausgefällt wird. Offensichtlich wird durch die Säurefällung eine zusätzliche Trübung erzeugt. Welche Faktoren hierfür verantwortlich sind, muß zunächst offenbleiben. Der KCN-Zusatz ist bei allen trüben Seren zu empfehlen. Bei den Eiweißbestim- mungen im "durchschnittlichen Normalserum" liegt der Fehler durch Trübung und/oder Farbstoffbeimengungen um $10 \%$ oder darunter. Tageszeitliche Schwankungen des Eiweißgehaltes und Veränderungen durch orthostatische Belastungen liegen in der gleichen Größenordnung oder șind sogar etwas größer. Bei Berücksichtigung des methodischen Fehlers wird hier der KCN-Zusatz allein nur wenig zur besser reproduzierbaren Bestimmung des Serumgesamteiweißes beitragen.

Der in dieser Arbeit bestimmte Biuretfaktor für Rinderalbuminlösung ohne $\mathrm{KCN}-$ Zusatz stimmt gut mit dem von Beisenherz und Mitarbeitern (5) angegebenen Wert überein. Die leichte Trübung der untersuchten Albuminlösungen ist wahrscheinlich auf den Gehalt an langkettigen Fettsäuren zurückzuführen, der von Präparation zu Präparation etwas schwankt (15). Der höhere Faktor für Mitochondrieneiweiß ist zum Teil durch den Stickstoffgehalt anderer Substanzen in diesen Zellorganellen bedingt. So enthalten nach REDFEARN (14) Schweineherzmitochondrien 0,38 g Phosphorlipide pro g Protein. Dies entspricht einem PhosphorlipidStickstoffanteil am Gesamtstickstoff von etwa 5\%. Der Stickstoff aus Adeninnucleotiden fällt wegen der geringen Konzentration dieser Substanzen in Mitochondrien kaum ins Gewicht. Bei einer Erhöhung des Faktors um $10 \%$ muß nach Berücksichtigung des Phosphorlipidstickstoffs auch eine andere Proteinzusammensetzung der Mitochondrien für die verbleibende Differenz in Erwägung gezogen werden.

\section{Literatur}

1. Frank, H. und P.-H. Koecher, Dtsch. Arch. klin. Med. 197, 181 (1950). - 2. KIrk, P. L., Adv. Protein Chemistry 3, 139 (1947). - 3. Cornall, A. G., C. J. Bardawill und M. M. David, J. biol. Chemistry 177, 751 (1949). - 3a. WeICHSELbAuM, T. E., Amer. J. Clin. Path. Techn. Suppl. 10 (1946). - 4. Young, E. G., in: „Comprehensive Biochemistry" Bd. 7,1; Hrsg. M. Florkin und E. H. Stotz Elsevier Publishing Company, Amșterdam, London, New York (1963). - 5. BeIsenherz, G., H. Boltze, T. BüCHER, R. Czok, K. H. Garbade, E. Meyer-Arendt und G. Pfleiderer, Z. Naturforsch. 8b, 555 (1953). - 6. Stanley, P. G., Nature London 197, 1108 (1963). - 7. KINGSLEY, G. R., J. Laborat.
Clin. Med. S. Louis 27, 840 (1942). - 8. Schollmexer, P. und M. Kinngenberg, Biochem. Z. 335, 426 (1962). - 9. Camerino, P. W. und L. Smith, J. biol. Chemistry 239, 2345 (1964). - 10. Hoskins, D. D. und R. A. BJuR, J. biol. Chemistry 239, 1856 (1964). - 11. Szarkowska, L. und M. KLINGENBERG, Biochem. Z. 338, 674 (1963). - 12. Bode, Ch. und M. KLINGenderg, Biochem. Z. 341, 271 (1965). - 13. RAPPAPORT, F. und G. EICHHORN, Lancet London 1947/II, 171. - 14. RedFEARN, E. R., in: „Biol. Structure and Function“ Vol. II S. 181. Hrsg. F. W. Goodwin und O. Lindberg, Academic Press, London, New York (1961). - 15. Schulze, H. Persönliche Mitteilung.
Dr. Ch. Bode 355 Marburg/Lahn Mannkopffstr. 1 